\title{
What About the First One-Hundred Days at a Community College Architecture Program?
}

RANDY A. STEINER

Montgomery College

"There is no single path to success."

Harvey Graff, Professor of Literary Studies and History, Ohio State University, and author, Undisciplinary Knowledge: Interdisciplinary in the 20th Century

Where do we start as future architects? Are we fascinated by the social impact of our design solutions? Are we intrigued with the possibilities of materials and their structural potential? Are we so fond of problem solving that anything read in English literature or studied in Biology spurs our creativity?

Perhaps there is no single start to our paths.

One foundation could be at the community college architectural program [CCAP]. The first hundred days for an architecture student can be magical but alarming. There is much to learn.

How do we merge the marching with imagination through academics and then, the smacking into the reality of the workplace? Based on data collected from over 120 CCAPs, this proposal offers the teaching within the community college architecture program as an alternate "Beginning Design Pedagogy."

First, it will address offering a wide range of architectural courses in the first semester to beginning architectural students. Second, it will address the ethical responsibility of educators to provide future architects of the 21st century with appropriate skills for the 21st century profession. Lastly, it will address the need to adapt to the learning style of members of the current students.

OVERVIEW OF COMMUNITY COLLEGE ARCHITECTURE PROGRAMS [I.E. CCAPS]

\section{A) DATA ABOUT NUMBERS OF CCAPS}

According to the American Association of Community Colleges or AACC, "In January 2016, there were 982 public community colleges registered with the AACC in the USA along with 90 private and 38 tribal colleges." [1] According to the Association of American Colleges and Universities, there are over 4,600 higher education institutions across the USA as of 2014. [2]
There are over 120 community colleges in the USA which offer 60-credit degrees in Architectural Technology, Architectural Design, or Architecture depending on their college's nomenclature. I began the research on the nation's community college architecture programs while on a semester sabbatical in 2007 and continued the study while returning to my position as coordinator of the Architecture Program at Montgomery College in Rockville, Maryland and serving as President of the Potomac Valley Architecture Foundation, a non-profit wing of the AIA Potomac Valley in Maryland. After identifying the many programs along with the name and address of the coordinators and their curriculums, I prepared a 30-question survey and tracked down survey responses. By March 2014, there were 122 responses!

\section{B) DATA ABOUT CCAPS BASED ON 122 SURVEYS Number and Location of CCAPS:}

The average year that CCAPs were founded was 1974 with three dating back to the 1940's. The greatest number of CCAPs are in California, Florida, Illinois, Pennsylvania, and Texas. There are no CCAPs in Arkansas, Georgia, Idaho, Oklahoma, Mississippi, Montana, Puerto Rico, Rhode Island, and Vermont.

Faculty Profiles of CCAPs:

The average number of faculty members is 8 members with an average of 3 full-time and 5 part-time. The breakdown by gender and other is $12 \%$ female members and $15 \%$ minority members. The average Faculty to Student ratio is 1 to 18 .

Cost and breakdown by degree type:

The average cost of a 60 -credit degree is $\$ 8,700$ based on an average $\$ 145$ per credit. The average number of semesters required to compete such a degree is 5.5 semesters. [The causes for the extra 1.5 semesters could be part-time enrollment, family obligations, college preparedness, cultural and social commitments among other reasons.] Associate of Arts + Sciences [AAS] degrees were awarded at $89 \%$ of the CCAPs; Associate of Sciences [AS] degrees accounted for $34 \%$ of the CCAPs and Associate of Arts [AA] degrees were awarded at $11 \%$ of the CCAPs. 
Student Population of CCAPs:

The average number of graduates per CCAP in 2014 was 20 students. The average number of first year architecture majors was 48 students and the average number of architecture majors was 86 students. The percentage of architecture majors who were full-time [ 12 credits] was $67 \%$ and those who self-identified as minority was $40 \%$.

\section{C) HISTORY OF THE COALITION OF COMMUNITY COLLEGE ARCHITECTURE PROGRAMS [I.E. CCCAP]}

The Coalition of Community College Architecture Programs [i.e. CCCAP] was created in 2012 in the Wright Room of the AIA National Headquarters with an attendance of 22 CCAP faculty members and 1 dean of an ACSA-accredited school. The CCCAP developed a mission statement and proceeded immediately to submit recommendations to the NAAB regarding the 2014 Accreditation Standards. In March 2014, the CCCAP became a non-profit $501.3 \mathrm{c}$ organization and has held annual conferences since 2012. The CCCAP is a membership organization including Full Membership for CCAPs, Institutional Membership for architectural institutions offering undergraduate degrees, Corporate Membership, and Individual Membership. The Sixth Annual CCCAP Conference will be held in New York City on June 23, 2018.

The CCCAP established its first CCCAP Student Design Competition in 2015 and has continued to offer 1st and 2nd year architecture students a chance to compete. The CCCAP Student Design Competition 2018 is a Visitor Center on the Joshua Tree National Park. Images of winning designs are available at www.cccap.org. as welll as info on the 2018 competition.

\section{OFFER A WIDE RANGE OF ARCHITECTURE COURSES FROM DAY ONE}

\section{A) ONLY 10\% OF COMMUNITY COLLEGES OFFER ARCHITECTURE PROGRAMS}

Most community colleges are public post-secondary institutions and are mandated by their state to restrict their degree requirements to sixty [60] credits. Most four-year institutions, public and private, maintain their four-year undergraduate degree requirements to 120 credits with a maximum of 60-90 transfer credits. While the purposes of many community college are lifetime learning, remedial education, or technical certification, additionalte goals are often career exploration and transfer to allow seamless transiton to continue in the chosen career.

Approximately, $10 \%$ of the total 1108 community colleges in the USA have degree-awarding architecture programs in their colleges. Although the percentage is smaller than the number of nursing and engineering programs, these architecture programs graduated 1,906 students in 2014 ! At least $75 \%$ of those who were first semester architecture majors continued on to complete their degree. What kept them so motivated in such a demanding program? What did they learn and achieve after those 60 credits?

I believe one answer is the wide range of architecture courses in their first semester as architecture majors. The students are engaged in their wonder about architecture head on! The variety of educational experiences from manual drawing to reading -based introductory courses to construction based lectures on buildable materials and methodology is offered in their first semester. The "Beginning Design Pedagogy" within the CCAP is a foundation of both conceptual and technical learning.

\section{B) DATA BASED ON FIRST SEMESTER PLANS OF 24 CCAPS}

\begin{tabular}{|c|c|c|c|}
\hline 1 & \multicolumn{3}{|c|}{ GENERAL EDUCATION REQUIREMENTS IN 1ST SEMESTER } \\
\hline 2 & English Composition & 3 & $\begin{array}{l}79 \% \text { of all } 24 \\
\text { CCAPs }\end{array}$ \\
\hline 4 & Math [Calculus or PreCalculus] & 5 & $\begin{array}{l}66 \% \text { of all } 24 \\
\text { CCAPs }\end{array}$ \\
\hline 6 & $\begin{array}{l}\text { General Ed Distribution [Soc. Sci., Humanities, } \\
\text { Nat. Sci.] }\end{array}$ & 7 & $\begin{array}{l}25 \% \text { of alll } 24 \\
\text { CCAPs }\end{array}$ \\
\hline 8 & \multicolumn{3}{|c|}{ ARCHITECTURE COURSES REQUIRED IN 1ST SEMESTER } \\
\hline 9 & Introduction to Architecture & 10 & $\begin{array}{l}58 \% \text { of all } 24 \\
\text { CCAPs }\end{array}$ \\
\hline 11 & Architectural Graphics & 12 & $\begin{array}{l}33 \% \text { of all } 24 \\
\text { CCAPs }\end{array}$ \\
\hline 13 & Drawing/Fine Arts & 14 & $\begin{array}{l}21 \% \text { of all } 24 \\
\text { CCAPs }\end{array}$ \\
\hline 15 & Design & 16 & $\begin{array}{l}21 \% \text { of all } 24 \\
\text { CCAPs }\end{array}$ \\
\hline 17 & Drafting [manual] & 18 & $\begin{array}{l}41 \% \text { of all } 24 \\
\text { CCAPs }\end{array}$ \\
\hline 19 & $\begin{array}{l}\text { Architectural Electives [ex. History of } \\
\text { Architecture] }\end{array}$ & 20 & $\begin{array}{l}33 \% \text { of all } 24 \\
\text { CCAPs }\end{array}$ \\
\hline \multicolumn{4}{|c|}{21 CAD/CONSTRUCTION MANAGEMENT REQUIREMENTS } \\
\hline 22 & CAD & 23 & $62 \%$ of all CCAPs \\
\hline 24 & Methods + Materials of Construction & 25 & $54 \%$ of all CCAPs \\
\hline
\end{tabular}

\section{C) POSITIVE POTENTIAL OF OFFERING WIDE RANGE} OF ARCHITECTURE COURSES FROM DAY ONE

In CCAPs, architecture majors spend 66\% [two-thirds] of their time during their first fifteen weeks immersed in architecture-related courses in small classes of 24 or less students with faculty who only teach a limited range of architecture courses. Students develop cohorts among themselves as many attend the same classes. Beginning college for a recent high school graduate or a non-traditional older person can be a jolt during the first months. Becoming familiar with people early in your academic life who share your same interests creates an intangible bond which can reinforce learning.

Listed are "Learning Outcomes" prepared by the CCAPs in this study which express their goals for the graduates. To achieve such lofty goals, CCAPs start from Day One. 
- Assemble building materials and systems

- Analyze how the history of architecture influences current design

- Discuss what non-design factors influence building design

- Demonstrate the ability to organize a building program into a structure from functional and aesthetic perspectives

- Develop three-dimensional utilization abilities through abstract design exercises

- Demonstrate architectural presentation techniques in both manual and digital formats

- Create architectural solutions to a set of project requirements

- Identify building and material systems that are responsive to the major requirements of a project

- Display a sense of craft evidenced through neatness, clarity and precision

- Communicate graphically, orally and in writing to present architectural ideas

\section{D) EXAMPLE OF CCAP ASSIGNMENTS AND STUDENT WORK FROM FIRST SEMESTER}

College of DuPage, Glen Ellyn, IL

Project \#2 The Barcelona Pavilion in Plan, Elevation, and

Analysis [ARCH1121 Architectural Design + Communication]

In the first part of this course you have mastered a variety of drawing and drafting techniques for representing objects. In this assignment you will apply one of those techniques to an architectural masterpiece, The Barcelona Pavilion, by Ludwig Mies van der Rohe, 1928-1929, Barcelona, Spain.

Through this analysis and your previous analysis of the physical form you will begin to understand the ideas that the architect was exploring and how he developed them into a physical expression.

You will also explore the interaction between the occupants and the space and the space and the site. The analysis will include how occupants perceive the space, the visual lines that transcribe the structure and the formal systems that organize it. How occupants understand the space, relationships of parts to whole and other formal relationships. How occupants move through the space, the circulation paths within the structure, and how they occupy the space statically.

\section{Basic Goals:}

- To be able to accurately draft a plan oblique view of a complex object with a high degree of craft and precision using hand drafting and tools.
- To be able to draft to scale

- To be able to translate data from one scale to another using a graphic scale

- To be able to accurately and completely understand and interpret a set of orthogonal drawing

City College of Chicago, Chicago, IL

Project 3D Design of Many Pattern [ARCH121 Basic Design]

Project: To reconstruct a pattern using previously created patterns and constructed in 2D and 3D with AutoCAD

Objectives: Students will demonstrate a sense of craft in precision and care in the presentation as well as problem solving in creating a 3D pattern of another's design.

\section{PROVIDE FUTURE ARCHITECTS WITH 21ST CENTURY SKILLS FROM DAY ONE}

How do we will address the ethical responsibility of educators to provide future architects of the 21st century with appropriate skills for the 21st century profession? The A.R.E. 5.0 exam has evolved. The six divisions include a range of practical and technical topics with the elimination of and eliminated the famous "Schematic Design" section in 1999. Good design is without a doubt the backbone of good architecture but other aspects have garnered importance in the recent past.

\section{NCARB INTEGRATED PATH TO ARCHITECTURAL LICENSURE (IPAL) INITIATIVE}

In 2015, the National Council of Architectural Registration Boards (NCARB) announced the IPAL "The road to licensure for architects is getting shorter and shorter, thanks to a recent initiative spearheaded by the NCARB. The Integrated Path to Architectural Licensure (IPAL) provides students the opportunity to complete requirements for licensure while they are still earning their degree. Through the initiative, schools are encouraged to incorporate the Architectural Experience Program (AXP, formerly the Intern Development Program) directly into the curriculum, as well as the opportunity to take the Architect Registration Examination (ARE)." [3]

As of December 2017, there were 26 universities and colleges in the IPAL program. Licensure, which is required by a majority of the fifty states and governing agencies in Canada, usually takes a few years of intense study and rigorous examinations after one's initial formal education is complete to attain. The in-school program will enable students to take the ARE while enrolled in school. Each school's IPAL participation is unique, with faculty and staff developing individual schedules for review and acceptance by NCARB. Advantages to participating in an IPAL Program include focused opportunities to work in design firms while earning a degree, the option of taking the six ARE exams before graduation, and the chance to build a professional network while in school. 


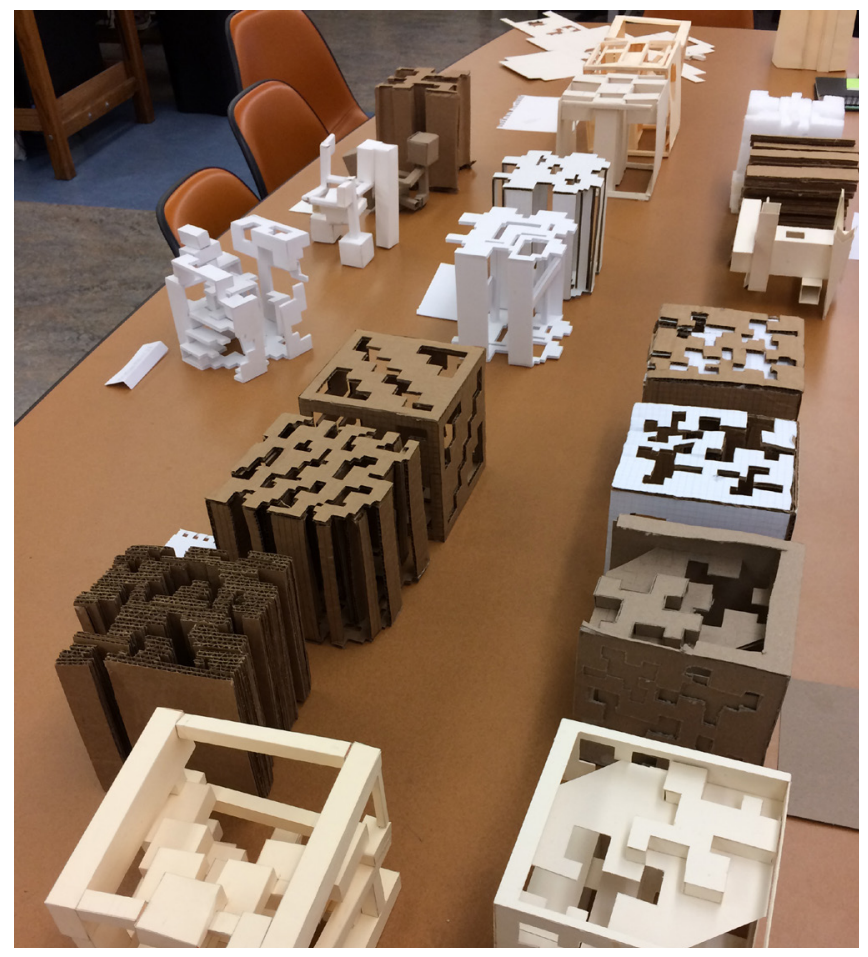

First Semester Class: ADC101 Introduction to Architecture + Construction [courtesy of Community College of Philadelphia/ Professor E. Masters]

Thirteen of the 26 IPAL programs have transfer relationships with CCAPs. The creation of ARE-inclusive curriculum/ assignments is in the start-up phase but the recognition of the need for change was a bold step for the IPAL schools and the profession. The NCARB has reached out to CCAPs as well as ACSA-accredited schools to provide volunteer 'Architect Licensing Advisors' to help navigate all students towards licensure.

The NCARB "2012 Practice Analysis of Architecture" was a massive study. "When licensed architects were asked, 'when should the knowledge/skill be acquired,' the overwhelming response across all $\mathrm{K} / \mathrm{S}$ statements was 'before completion of the accredited degree program.' While practitioners' expectations are not surprising, it fails to recognize the academy's struggle with a crowded curriculum and stretched resources.

Fifteen K/S [Knowledge/Skills] rated as important or greater were identified by more than 50 percent of all licensed architects as being acquired 'after licensure.' Ideally, all K/S rated important should be acquired prior to licensure. While this is rarely the case, the data does indicate a positive trend as recently licensed architects responded that they are acquiring many important K/S during education and internship." [4]

\section{ADAPT TO MULTI-MEDIA TEACHING AS TECHNOLOGY CHANGES SO RAPIDLY FROM DAY ONE}

Lastly, new models of "Beginning Design Pedagogy" need to be developed to adapt to the learning style of current/future architecture students. Generation Z [born between 1998 and
2004] has never seen a world without the Internet! The Z'ers consider technology an extension of themselves - it is their source of entertainment, education, and most importantly, their way of gathering, sharing, and interpreting information. They have a growing 'neuroplasticity', the ability to filter and process enormous amounts of information, efficiently and with purpose. They are used to jumping in head first.

“Neuroplasticity can be defined as brain's ability to change, remodel and reorganize for purpose of better ability to adapt to new situations. "[5] Neural networks are not fixed, but occurring and disappearing throughout our life, depending on experiences. According to a surge of psychological study today, after a neuronal development of the brain in infants, the adult brain changes by finding and defining major and minor neural pathways to support new activities or damage. Like muscle memory, the brain develops through repetition of movements such as learning to type or walk. Yes, we can all eventually achieve these skills but the earlier our brains create the pathways the stronger could be our abilities.

To support the multi-tasking inclination of the current generation of future architects, we should consider exposing them to the constructability and put-it-togetherness of buildings early in their education.

\section{CONCLUSIONS}

The community college architecture program offers a highly attractive option to how one approaches an architectural education in the constantly changing environment today. Early in the understanding of design and building science, offer a wide range of topics early, provide technical skills and adapt to the amazing new learning styles of the 21st century. It's another path to success.

\section{BIBLIOGRAPHY}

26 Brown, Jesse and Kurzweil, Martin. The Complex Universe of Alternatie Postsecondary Credentials and Pathways (Cambridge, Mass.: American Academy of Arts \& Sciences, 2017).

27 Graff, Harvey. Undisciplinary Knowledge: Interdisciplinary in the 20th Century (Baltimore, Maryland: Johns Hopkins University Press, 2015).

Jenkins, Rob. "Pressing Our Advantage." The Chronicle of Higher Education 27 June 2017.

Selingo, Jeffrey J. "Undergraduate education is broken. Solutions start with faculty and rigor." Washington Post 27 June 2017:B4. Print.

\section{ENDNOTES}

1 Statistics On Community Colleges. (n.d.). Retrieved from https://www.statista. com/statistics/421266/community-colleges-in-the-us/

2 Statistics On Colleges. (n.d.). retrieved from https://www.statista.com/ statistics/240833/higher-education-institutions-in-the-us-by-type/

3 IPAL. (n.d.). Retrieved from https//archinect.com/news/article/149982604/ architecture-students-at-17-schools-will-get-licensed-quicker-with-help-fromncarb-s-new-licensure-program-ipal/

4 National Architectural Registration Council Board. 'The 2012 Analysis of Architecture Report' (Washington, DC: NCARB, 2012).

5 Bene, Raphael and Demarin, Vida and Morovic, Sandra. "Neuroplasticity." Periodicum Biologorum, VOL. 116, No 2, 209-211, 2014." 
ARCH 2470. DESIGN III. PRDJECT II.

DIWNTIWN ART SCHRIL \& MUSEUM.

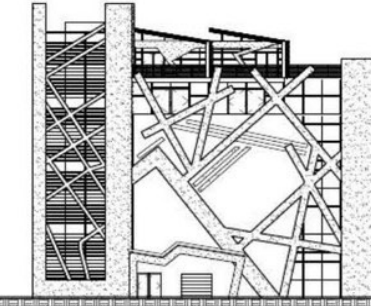

溜 ELEVATION 1

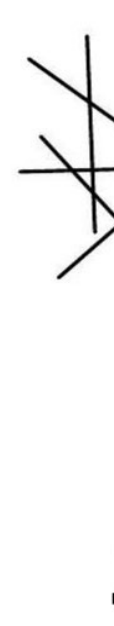

Elevation 2
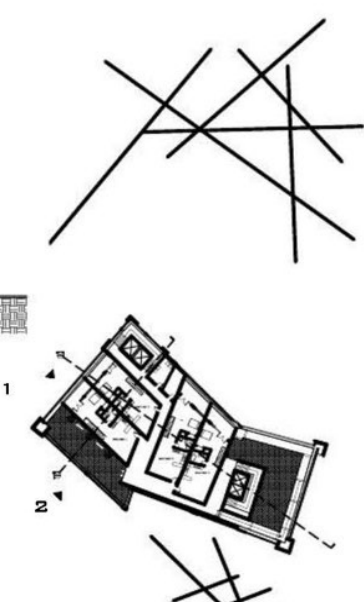

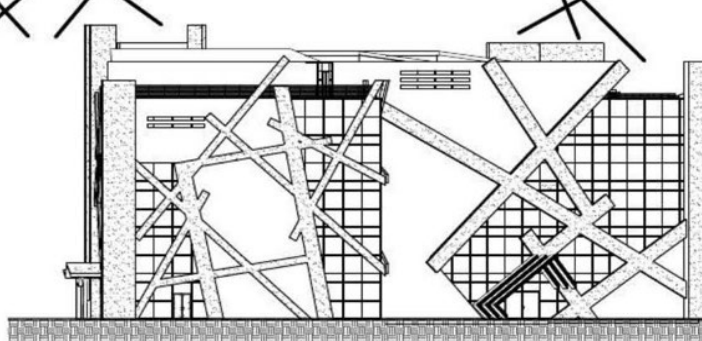

ABOVE: Second Semester ARCH2470 Architectural Design Studio II

[Courtesy of El Paso Community College/Professor K. Gorski] BELOW: Fourth Semester ARC252 Introduction to REVIT [Courtesy of Scottsdale Community College]
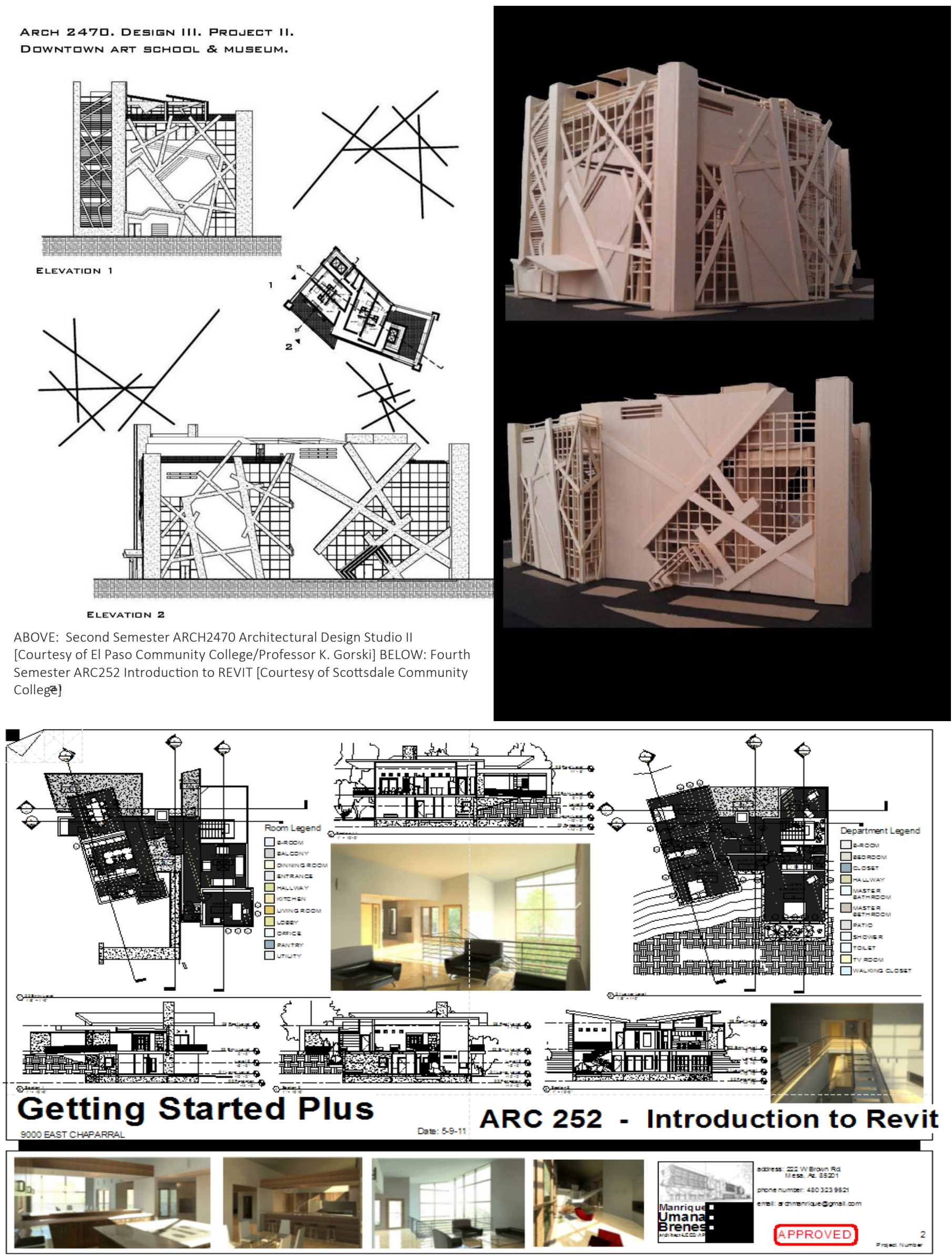